\title{
Garden Monitoring and Automation Using Atmega 16
}

\author{
Lakita Bharti ${ }^{1}$, Mohit Chandrapuri ${ }^{2}$, Varsha Nagle $^{3}$, Praveen Dhurve ${ }^{4} \&$ Jyoti Patil $^{5}$ \\ ${ }^{1,2,3,4,5}$ Shri Balaji Institute of Technology and Management, Betul, Madhya Pradesh, India.
}

As we know that plants are the essential part of our life. Plants always need good care for their growth. Plants may not survive when there is any deficiency of nutrition in the soil and environment. So, through this project we will make our gardens take care of itself. In this project the sensor we have used monitors the soil moisture and air temperature of the plants and then automatically it starts watering the plant on the basis of the data received from various sensors in our project. Maintenance and monitoring of our plants and gardens are important. We have to maintain the plants regularly so that they can also be prevented from pests. That is why this project helps the garden care for itself if someone is not present for their maintenance.

Keywords: Microcontroller, sensors, automation, maintenance of garden.

\section{INTRODUCTION}

As we know that plants play a vital role in maintaining the carbon dioxide and oxygen in air. Many plants die due to urbanization. But apart from it plants also die due to lack of maintenance. Gardening is a healthiest hobby anyone can adopt. But they need continuous care without break. So the main aim of this project is to provide proper care to the plants. This project will also ease the gardening. It is built using AVR Microcontroller and bunch of electronic sensors. In this project we have used soil moisture sensor, temperature sensor for calculating the moisture in the soil and temperature of the environment respectively. We have used IR Module sensor for monitoring the entry and exit of any person inside the garden. This IR Module also calculates the number of person entering in the garden. LDR is used here so that it can track if it is day or night. The controller is interfaced with the LCD display where it displays the data received from various sensors. The controller is programmed using embedded C. The AVR Studio is used to write, edit and compile code for ATmga16.

\section{COMPONENTS DESCPRITION}

\section{ATmega 16 Microcontroller}

Atmega16 is a 40-pin low power microcontroller which is developed using CMOS technology. It comes with low power consumption and high noise immunity.Atmega16 is an 8-bit controller based on AVR advanced RISC

\begin{tabular}{|l|l|}
\hline Operating Voltage & For ATMEGA16:+4.5 to +5.5 V \\
\hline ADC Module & 8 channels, 10-bit resolution ADC \\
\hline Timer Module & Two 8-bit counters, One 16-bit counter \\
\hline External Oscillator & 0 -8MHz for ATMEGA16L \\
\hline Program Memory Type & Flash \\
\hline Program Memory & $16 \mathrm{Kbytes}$ \\
\hline Operating Temperature & $-55^{\circ} \mathrm{C}$ to $+125^{\circ} \mathrm{C}$ \\
\hline
\end{tabular}
(Reduced Instruction Set Computing) architecture. AVR is family of microcontrollers developed by Atmel in 1996.It is a single chip computer that comes with CPU, ROM, RAM, EEPROM, Timers, Counters, ADC and four 8-bit ports called PORTA, PORTB, PORTC, PORTD where each port consists of $8 \mathrm{I} / \mathrm{O}$ pins.Atmega16 has built-in registers that are used to make a connection between CPU and external peripherals devices. CPU has no direct connection with external devices. 


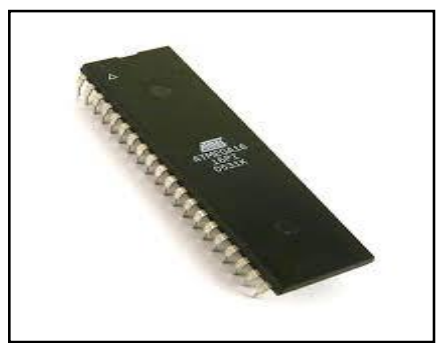

Fig.1 ATmega16 Microcontroller

\section{Soil Moisture Sensor}

The moisture sensor measures the volumetric water content of the soil with the help of a sensing probe which must be put into the soil. The sensor module operates between voltages of $3.3 \mathrm{~V}$ to $5 \mathrm{~V}$. The analog output pin of the sensor is connected to bit 1 of Port A of the AVR.

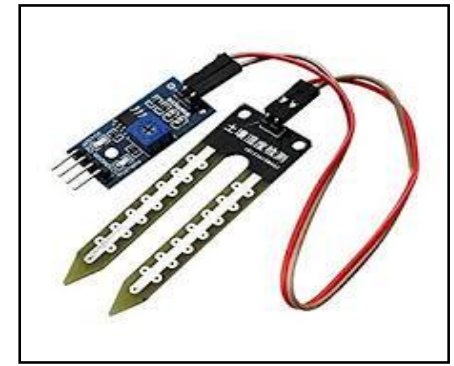

Fig.2 Soil Moisture Sensor

\section{Temperature Sensor}

LM35 is a popular temperature sensor. The sensor has three terminals - VCC, Output and Ground. The VCC and Ground terminals are connected to 5V DC and common ground respectively. The output terminal is connected to bit 2 of Port A of ATmega16.

\begin{tabular}{|l|l|}
\hline Range & $0^{\circ}-100^{\circ} \mathrm{C}$ \\
\hline Type & $5 \mathrm{kohm}$ NTC-resistors Max. wire resistance $3 \mathrm{Ohm}$ \\
\hline Power & +12 Volt $3,5 \mathrm{mAmp}-5$ Volt $1 \mathrm{mAmp}$ \\
\hline
\end{tabular}

\section{IR Module}

The two modules are used to detect entrance and exit of a visitor. Each sensor module is built from a pair of IR Transmitter and IR Receiver.

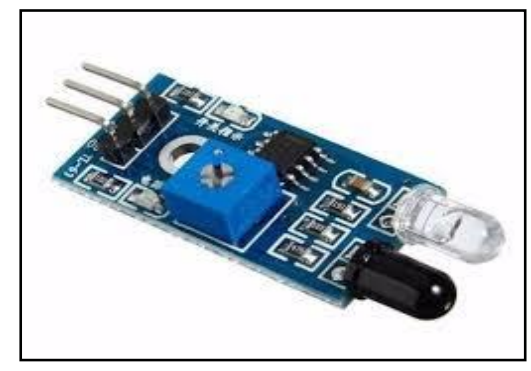

Fig.3 IR Module 
The emitter is simply an IR LED and the detector is simply an IR photodiode which is sensitive to IR light of the same wavelength as emitted by the IR LED. The sensor module has a digital output.

\section{$L D R$}

It is used to detect day and night in this circuit. This sensor is two- terminal sensitive resistor. It is connected as a voltage divider network at bit 0 of Port A of ATmega16.

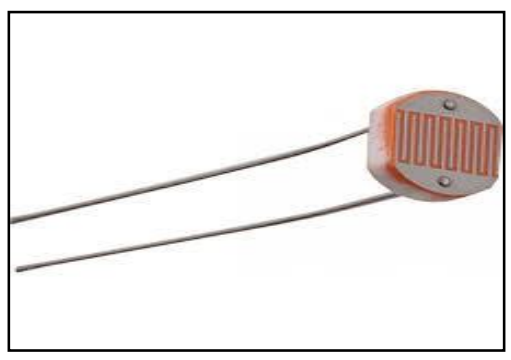

Fig.4 LDR

\section{Motor}

A DC motor is interfaced at bit 5 of Port D of the AVR. This pump is interfaced to the controller with the help of the relay $5 \mathrm{~V}$ relay.

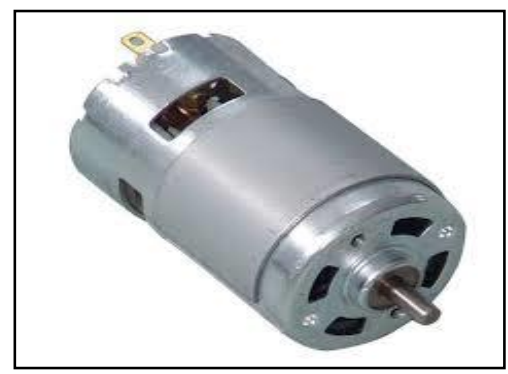

Fig.5 DC Motor

\section{BLOCK DIAGRAM}

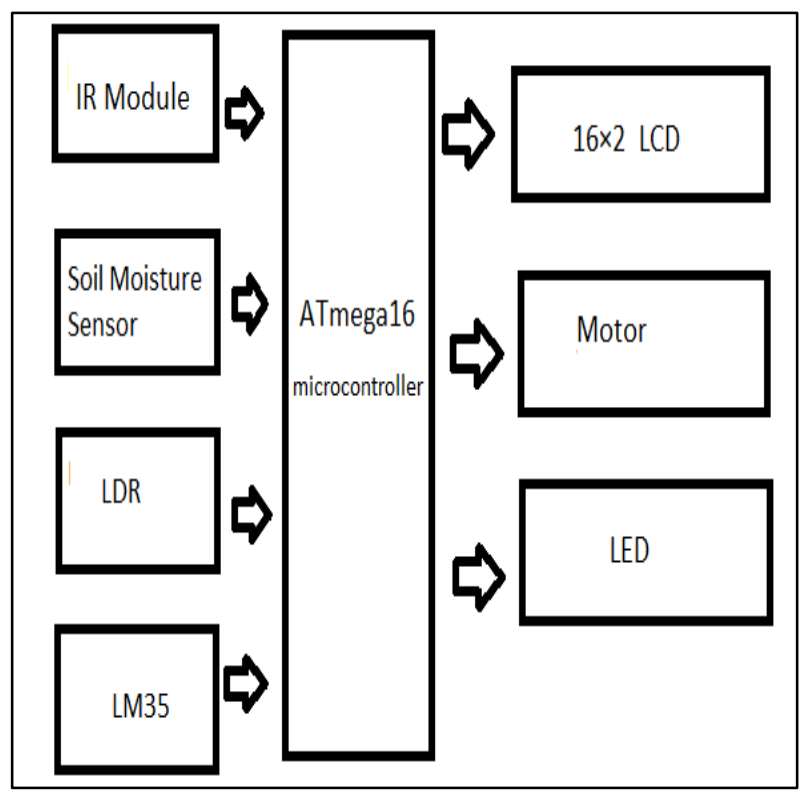




\section{SOFTWARE}

This system is based on AVR ATmega16. It is programmed in embedded C using AVR Studio 4. Other programming tools like Atmel Studio or Notepad++ can also be used to write and compile the code. First of all, user needs to add LCD library given below in zip file then copy and paste the code in AVR Studio 4 to generate hex file. Here, ATmega16 is used for sensing the condition of garden and take appropriate actions to control the gardening equipments like motor and lights. The LCD is interfaced with atmega16 to monitor the value of ambient temperature and soil moisture via sensors.

\section{CONCLUSION}

The implementation of Garden Monitoring and Automation System has been verified to satisfactorily work. The system designed not only monitors and display the moisture in the soil, temperature but also actuates other parameters like it supply water to the whole garden with the help of pump used when the soil goes dry and then automatically stops when the moisture in the soil is increased. The cost of installation of this system is low and hence it can be evaluated anywhere. We can also make use of various other new technologies to make the project more automated and self-controlled. This system saves manpower as well as time and hence it is profitable in economic terms.

\footnotetext{
REFERENCES

[1] T.Thamaraimanalan, S.P.Vivek, G.Satheesh kumar and P.Saravanan, "Smart Garden Monitoring System Using IOT" Asian Journal of Applied Science and Technology (AJAST) (Open Access Quarterly International Journal)" Volume 2, Issue 2, Pages 186-192, April-June 2018.

[2] Source: www.electronicshub.org/automatic-street-light-controller-using-relays-and-ldr/

[3] Sandhya.B.R, Pallavi.M, Chandrashekar.M "IoT Based Smart Home Garden Watering System Using Raspberry Pi 3" International Journal of Innovative Research in Science, Engineering and Technology (An ISO 3297: 2007 Certified Organization) Vol. 6, Special Issue 12, July 2017.

[4] Parmod Kumar, Ankur Sharma, Rashid Hussain, "WSN Application: Intelligent Drip Irrigation System Through Moisture and Temperature Sensors" Volume 3, 2014, International Journal of Scientific Research Engineering and Technology (IJSRET) ISSN2278-0882.

[5] Jasmine Sweety.A, Dharshika.S, Jabez.J and Maria Anu.V, "An Enhanced Automation of Garden Watering Based On IOT" Global Journal of Pure and Applied Mathematics ISSN 0973-1768 Vol. 13, Number 6 (2017), pp. 2181-2191.

[6] Nagarajapandian M, Ram Prasanth U, Selva Kumar G, and Tamil Selvan S, "Automatic irrigation system on sensing soil moisture content," IJIREEICE, pp. 96-98, 2015.

[7] P. Lashitha Vishnu Priya, N. Sai Harshith, Dr. N. V. K.Ramesh, "Smart agriculture monitoring system using IoT" International Journal of Engineering \& Technology, 7 (2.7) (2018) 308-311.
} 